\title{
Early Results of Coronary Artery Bypass Graft (CABG) in Patients with Low Ejection Fraction
}

\author{
Wassam El-Din Hadad El-Shafey ${ }^{1}$, Taher Mohamed Ahmed Elnagar², \\ Ahmed Abdalla Mostafa Kamal ${ }^{3}$, Abdalla Mostafa Kamal ${ }^{1}$ \\ ${ }^{1}$ Cardiology Department, Faculty of Medicine, Menoufia University, Al Minufya, Egypt \\ ${ }^{2}$ Cardiology Department, National Heart Institute, Cairo, Egypt \\ ${ }^{3}$ Cardiology Department, Police Academy, Cairo, Egypt \\ Email: dr_wesamhadad@yahoo.com
}

How to cite this paper: El-Din Hadad El-Shafey, W., Elnagar, T.M.A., Kamal, A.A.M. and Kamal, A.M. (2020) Early Results of Coronary Artery Bypass Graft (CABG) in Patients with Low Ejection Fraction. World Journal of Cardiovascular Diseases, 10 , 319-328.

https://doi.org/10.4236/wjcd.2020.105030

Received: March 27, 2020

Accepted: May 24, 2020

Published: May 27, 2020

Copyright $\odot 2020$ by author(s) and Scientific Research Publishing Inc. This work is licensed under the Creative Commons Attribution International License (CC BY 4.0).

http://creativecommons.org/licenses/by/4.0/

\section{(c) (i) Open Access}

\begin{abstract}
Background: Patients with ischemic heart disease and reduced ejection fraction have increased risk for postoperative complications and mortality. Our aim was to evaluate the effect of low EF $(<40 \%)$ on the early outcomes after CABG and identify the predictors of mortality. Methods: From August 2018 to November 2019, 170 consecutive patients underwent CABG. Group 1 included 120 patients with EF (<40\%; $37.49 \pm 2.89 \%)$; 94 were men $(78.3 \%)$, and the mean age was $55.83 \pm 8.04$ years. Group 2 included fifty patients having EF $(>40 ; 57.90 \% \pm 2.27 \%), 41$ were men $(82.0 \%)$, and the mean age was $54.30 \pm 7.01$ years and used as a control group. Results: Overall 30-day mortality was $10 / 120$ patients (8.3\%). Factors associated with higher mortality were females $(70.0 \%$ vs. $17.3 \%, \mathrm{P}<0.001)$; older age $(61.40 \pm 7.01$ vs. $55.32 \pm$ 7.97 years, $\mathrm{P}=0.025)$; diabetes mellitus $(100 \%$ vs. $51.8 \%$; $\mathrm{P}=0.003)$; longer cardiopulmonary bypass time (148.70 \pm 40.12 vs. $108.49 \pm 36.89 \mathrm{~min} ; \mathrm{P}=$ $0.012)$; longer cross clamp time $(88.19 \pm 31.94$ vs. $64.77 \pm 22.67 \mathrm{~min} ; \mathrm{P}=$ $0.049)$, longer total operative time $(6.82 \pm 1.03$ vs $5.38 \pm 0.95$ hours; $\mathrm{P}=$ 0.001); intra-aortic balloon pump (IABP) insertion (90.0\% vs. $10.9 \%$; $\mathrm{P}<$ $0.001)$; intra-operative complications ( $60 \%$ vs. $1.8 \%, \mathrm{P}<0.001)$; ventricular tachycardia and ventricular fibrillation $(30 \%$ and $50 \%$ vs. $4.5 \%$ and $5.5 \%$ respectively; $\mathrm{P}=0.002$ for both); myocardial infarction $(70 \%$ vs $11.8 \%, \mathrm{P}<$ $0.001)$, and lower postoperative ejection fraction $(21.46 \pm 1.93$ vs $40.30 \pm$ $8.19 \%, \mathrm{P}<0.001)$. In patients with low EF, postoperative NYHA and CCS angina class have improved compared to the preoperative levels $(1.50 \pm 0.61$ vs. $3.31 \pm 0.56 ; \mathrm{P}<0.001$ and $1.38 \pm 0.52$ vs. $3.11 \pm 0.55 ; \mathrm{P}<0.001$ respectively). Conclusion: $\mathrm{CABG}$ in $\mathrm{EF}<40 \%$ is associated with more complications compared with those had EF higher than 40\%; however, the clinical and
\end{abstract}


echocardiographic parameters improved over time.

\section{Keywords}

Coronary Artery Bypass Graft Low, Ejection Fraction

\section{Introduction}

Ischemic heart disease is one of the major causes of death, disability and health care resource utilization worldwide but recent advances in operative techniques and perioperative care have resulted in an increasing number of elderly patients undergoing coronary artery bypass grafting (CABG) with significant improvements in health-related quality of life as a marker of outcome after CABG [1].

$\mathrm{CABG}$ is one of the most common surgical procedures performed worldwide. The operation improves survival as well as the quality of life of patients with coronary artery heart disease. The use of the internal mammary artery (IMA) graft has become increasingly popular in CABG operations due to its demonstrated better long-term patency as compared with that of the saphenous vein graft [2].

CABG is very effective at relieving angina and improving survival, which are the primary indications for the operation. Traditional outcome measures assessing the quality of CABG have been morbidity and mortality. However, with improvements in perioperative care, cardiopulmonary bypass and surgical techniques, the overall mortality associated with $C A B G$ has declined despite an increasingly elderly and sicker patient cohort [3].

The low EF patients undergoing CABG are the subjects of ongoing research [4] [5]. These patients are at higher risk of postoperative complications; however, improved long-term outcomes were reported [6]. Our work aimed to assess the early clinical outcomes and the predictors of mortality in patients with low EF $(<40 \%)$ after coronary artery bypass graft.

\section{Patients and Methods}

\subsection{Study Setting}

This is a prospective cohort study performed between August 2018 and November 2019 on 170 patients with ischemic heart disease who had elective CABG at the National Heart Institute and Menoufia University Hospital. We exclude emergency patients, redo cardiac surgery, patients who needed concomitant cardiac surgery, very low $\mathrm{EF}(<20 \%)$.

All patients were subjected to a complete history taking, followed by comprehensive general and local cardiac examinations. Pre-operative Dobutamine stress echocardiography was done for all patients. The study was approved by the Ethical Committee. All patients provided written informed consents. Patients demographics are summarized in Table 1. 
Table 1. Patients' demographics. Values are presented as numbers (\%) or mean $+\mathrm{SD}$. * indicate significant difference between the groups $(\mathrm{p}<0.05)$.

\begin{tabular}{|c|c|c|c|c|}
\hline & & \multirow{2}{*}{$\begin{array}{c}\text { Group } 1 \\
\mathrm{EF}<40 \% \\
(\mathrm{n}=120)\end{array}$} & \multicolumn{2}{|c|}{$\begin{array}{c}\text { Group } 2 \\
\mathrm{EF} \geq 40 \%\end{array}$} \\
\hline & & & $(\mathrm{n}=50)$ & $P$ value \\
\hline \multicolumn{2}{|c|}{ Female } & $26(21.6 \%)$ & $9(18.0 \%)$ & 0.286 \\
\hline \multicolumn{2}{|c|}{ Age (years) } & $55.83 \pm 8.04$ & $54.30 \pm 7.01$ & 0.242 \\
\hline \multicolumn{2}{|c|}{ BMI $\left(\mathrm{Kg} / \mathrm{m}^{2}\right)$} & $29.89 \pm 4.55$ & $29.27 \pm 4.35$ & 0.413 \\
\hline \multicolumn{2}{|l|}{ Smoking } & $57(47.5 \%)$ & $26(52.0 \%)$ & 0.592 \\
\hline \multicolumn{2}{|c|}{ Dyslipidemia } & $58(48.3 \%)$ & $23(46.0 \%)$ & 0.781 \\
\hline \multicolumn{2}{|c|}{ Hypertension } & $65(54.1 \%)$ & $22(44.0 \%)$ & 0.226 \\
\hline \multicolumn{2}{|c|}{ Diabetics } & $67(55.8 \%)$ & $21(42.0 \%)$ & 0.100 \\
\hline \multicolumn{2}{|c|}{ Preoperative LVEDD (cm) } & $5.79 \pm 0.53$ & $5.44 \pm 0.56$ & $<0.001^{\star}$ \\
\hline \multicolumn{2}{|c|}{ Preoperative LVESD (cm) } & $4.58 \pm 0.70$ & $3.53 \pm 0.60$ & $<0.001^{*}$ \\
\hline \multicolumn{2}{|c|}{ Preoperative EF (\%) } & $37.49 \pm 2.89$ & $57.90 \pm 2.27$ & $<0.001^{\star}$ \\
\hline \multirow{7}{*}{$\begin{array}{l}\text { Preoperative } \\
\text { NYHA class \& } \\
\text { CCS grade }\end{array}$} & II & $6(5.0 \%)$ & $6(12.0 \%)$ & \multirow{3}{*}{0.113} \\
\hline & III & $70(58.3 \%)$ & $32(64.0 \%)$ & \\
\hline & IV & $44(36.7 \%)$ & $12(24.0 \%)$ & \\
\hline & & & & \\
\hline & II & $12(10.0 \%)$ & $9(18.0 \%)$ & \\
\hline & III & $82(68.3 \%)$ & $35(70.0 \%)$ & 0.165 \\
\hline & IV & $26(21.7 \%)$ & $6(12.0 \%)$ & \\
\hline \multirow{5}{*}{$\begin{array}{c}\text { Number of } \\
\text { diseased vessels }\end{array}$} & Single & $3(2.5 \%)$ & $3(6.0 \%)$ & \multirow{5}{*}{0.193} \\
\hline & 2 -vessels & $11(9.1 \%)$ & $8(16.0 \%)$ & \\
\hline & 3 -vessels & $38(31.6 \%)$ & $17(34.0 \%)$ & \\
\hline & 4 -vessels & $51(42.5 \%)$ & $20(40.0 \%)$ & \\
\hline & 5-vessels & $17(14.1 \%)$ & $2(4.0 \%)$ & \\
\hline
\end{tabular}

Inclusion Criteria: This study included:

1) Patients suffer from ischemic heart disease with complex lesions indicating Coronary Artery Bypass Grafting surgery after heart team opinion.

2) Age group (40 - 70 years).

\section{Exclusion Criteria:}

The following patients were excluded from our study:

1. Patients who need other cardiac surgery with CABG.

2. Redo cardiac surgery.

3. Very low EF $20 \%$.

4. Patients of other system failures (hepatic or renal failure). 
5. Patients with left main stem disease.

6. Emergency patients.

\subsection{Operative Techniques}

A standard median sternotomy was done in all patients. Saphenous vein grafts and Left Internal Mammary Artery (LIMA) were harvested. Cardiopulmonary bypass $(\mathrm{CPB})$ was established via cannulation of the ascending aorta, and cannulation of the right atrium was via single venous cannula. Surgery was performed under normothermia. The distal anastomoses were done at first then all proximal anastomoses were done after removal of aortic cross-clamp. Myocardial protection was achieved with an intermittent warm blood cardioplegia after every graft anastomosis.

The indications for IABP were: a) patients with ventricular arrhythmia (ventricular tachycardia (VT)); b) post-operative low cardiac output syndrome; c) failure of weaning from CPB despite maximum inotropic support; d) patients with low cardiac output after a "difficult" weaning from $\mathrm{CPB}$, supported by high-doses of inotropes. The IABP was inserted percutaneously through the common femoral artery.

After surgery, patients were transferred to the ICU. We started Weaning from mechanical ventilation in the absence of significant bleeding and hemodynamic instability and, as soon as an adequate level of consciousness and normothermia were achieved. Our therapy included, hydration, antibiotics, diuretics, antacids, and $\mathrm{d}$, as well as inotropic drugs and mechanical circulatory support devices when required. Myocardial infarction was defined according to the Consensus Conference for the Universal Definition of Myocardial Infarction [7]. Low cardiac output syndrome was defined as cardiac index below $21 / \mathrm{min} / \mathrm{m}^{2}$ despite adequate fluid replacement and systolic blood pressure $<100 \mathrm{mmHg}$ with signs of organ hypoperfusion (lactic acidosis, decreased urine output).

We followed all patients clinically and echocardiography at the outpatient clinic or contacted by phone periodically one and three months postoperatively.

\subsection{Statistical Analysis}

Data were collected, revised, coded and entered the Statistical Package for Social Science (IBM SPSS) version 20 (IBM Corporation, Chicago, IL, USA). While quantitative data with parametric distribution were presented as mean, standard deviations and ranges. Qualitative data were presented as number and percentages. The comparison between two groups with qualitative data was done by using the Chi-squared test or Fisher exact test when the expected count in any cell was found less than 5. Comparison between two independent groups regarding quantitative data with parametric distribution was done by using the independent t-test. Paired t-test was used to compare pre and postoperative changes in the low EF group. Comparison between more than two independent groups regarding quantitative data with parametric distribution was made by 
using One Way ANOVA.

\section{Results}

In regard to viability, the number of patients with total viable myocardium was 94 patients $(78.33 \%)$, while the partial non-viable myocardium was as the following: in the left anterior descending (LAD) artery territory 8 patients $(6.67 \%)$, in the right coronary artery (RCA) territory was 12 patients $(10.0 \%)$ and in the circumflex (LCX) artery territory was6 patients (5.0\%).

Table 2 shows the study outcomes. Nine patients (7.5\%) had surgical technique problems; In 2 patients, LAD could not be determined, 4 of them had dissected LIMA which was used as a free graft in one patient required re-anastomosis of LIMA to LAD and there was kinking of vein grafts to OM in one patient.

The improvements in NYHA classification, CCS grade and ejection fraction postoperatively were significant in comparison to the preoperative value as shown in Table 3.

Table 2. Operative and postoperative outcomes. Values are presented as numbers (\%) or mean + SD. ${ }^{*}$ indicate significant difference between the groups $(\mathrm{p}<0.05)$.

\begin{tabular}{|c|c|c|c|c|}
\hline & & $\begin{array}{c}\text { Group } 1 \\
\mathrm{EF}<40 \%\end{array}$ & $\begin{array}{c}\text { Group } 2 \\
\mathrm{EF} \geq 40 \%\end{array}$ & $\mathrm{P}$ value \\
\hline & & $(\mathrm{n}=120)$ & $(\mathrm{n}=50)$ & \\
\hline \multirow[t]{2}{*}{ Number of grafts } & & $3.12 \pm 1.00$ & $2.68 \pm 0.89$ & $0.007^{\star}$ \\
\hline & LIMA & $116(96.6 \%)$ & $48(96.0 \%)$ & 0.830 \\
\hline \multirow[t]{3}{*}{ Type of grafts } & RIMA & $7(5.8 \%)$ & $2(4.0 \%)$ & 0.626 \\
\hline & Radial & $6(5 \%)$ & $7(14.0 \%)$ & $0.044^{\star}$ \\
\hline & SV & $117(97.5 \%)$ & $47(94.0 \%)$ & 0.259 \\
\hline \multicolumn{2}{|l|}{ CBP time (min) } & $111.95 \pm 41.27$ & $103.40 \pm 54.98$ & 0.267 \\
\hline \multicolumn{2}{|l|}{ ACC time (min) } & $66.72 \pm 24.90$ & $62.54 \pm 40.82$ & 0.415 \\
\hline \multicolumn{2}{|c|}{ Total operative time (hours) } & $5.53 \pm 0.81$ & $5.12 \pm 1.03$ & $0.006^{\star}$ \\
\hline \multicolumn{2}{|l|}{ DC shock application } & $49(40.8 \%)$ & $16(32.0 \%)$ & 0.280 \\
\hline \multicolumn{2}{|c|}{ Surgical technique problems } & $9(7.5 \%)$ & $2(4.0 \%)$ & 0.398 \\
\hline \multicolumn{2}{|c|}{ Intra-operative complications } & $8(6.6 \%)$ & $2(4.0 \%)$ & 0.500 \\
\hline \multicolumn{2}{|l|}{ Re exploration } & $7(5.8 \%)$ & $3(6.0 \%)$ & 0.964 \\
\hline \multicolumn{2}{|c|}{ Mediastinal drainage (ml) } & $749.35 \pm 377.99$ & $694.34 \pm 390.94$ & 0.393 \\
\hline \multicolumn{2}{|c|}{ Duration of mechanical ventilation (hrs) } & $17.99 \pm 24.58$ & $16.98 \pm 26.16$ & 0.811 \\
\hline \multicolumn{2}{|l|}{ ICU stay (days) } & $3.75 \pm 1.93$ & $3.39 \pm 1.69$ & 0.252 \\
\hline \multicolumn{2}{|c|}{ Total hospital stays (days) } & $8.85 \pm 3.33$ & $7.93 \pm 4.10$ & 0.127 \\
\hline \multirow{2}{*}{$\begin{array}{l}\text { Postoperative cardiac } \\
\text { support }\end{array}$} & Adrenaline & $93(77.5 \%)$ & $26(52.0 \%)$ & $<0.001^{\star}$ \\
\hline & Dobutamine & $6(5.0 \%)$ & $1(2.0 \%)$ & 0.369 \\
\hline
\end{tabular}




\section{Continued}

\begin{tabular}{|c|c|c|c|c|}
\hline \multicolumn{2}{|l|}{ Levosimendan } & $14(11.6 \%)$ & $2(4.0 \%)$ & 0.118 \\
\hline \multicolumn{2}{|l|}{ IABP insertion } & $21(17.5 \%)$ & $3(6.0 \%)$ & $0.049^{\star}$ \\
\hline \multicolumn{2}{|l|}{ Superficial wound infection } & $11(9.1 \%)$ & $4(8.0 \%)$ & 0.806 \\
\hline \multicolumn{2}{|l|}{ Cerebrovascular events } & $6(5.0 \%)$ & $1(2.0 \%)$ & 0.369 \\
\hline \multicolumn{2}{|l|}{ MI } & $20(16.6 \%)$ & $5(10.0 \%)$ & 0.263 \\
\hline \multicolumn{2}{|l|}{ Non-fatal MI } & $13(10.8 \%)$ & $4(8.0 \%)$ & 0.574 \\
\hline \multicolumn{2}{|c|}{ Non-fatal cerebrovascular events } & $5(4.1 \%)$ & $1(2.0 \%)$ & $0.015^{*}$ \\
\hline \multicolumn{2}{|l|}{ Readmission for HF } & $5(4.1 \%)$ & $1(2.0 \%)$ & $0.015^{*}$ \\
\hline \multicolumn{2}{|l|}{ 30-days mortality } & $10(8.3 \%)$ & $1(2.0 \%)$ & 0.126 \\
\hline & I & $61(55.4 \%)$ & $29(59.2 \%)$ & \\
\hline \multirow[t]{3}{*}{$\begin{array}{l}\text { Post-operative NYHA } \\
\text { class }\end{array}$} & II & $42(38.2 \%)$ & $18(36.7 \%)$ & 0.813 \\
\hline & III & $7(6.4 \%)$ & $2(4.1 \%)$ & \\
\hline & I & $70(63.6 \%)$ & $31(63.3 \%)$ & \\
\hline \multirow[t]{2}{*}{ Postoperative CCS grade } & II & $38(34.6 \%)$ & $17(34.7 \%)$ & 0.995 \\
\hline & III & $2(1.8 \%)$ & $1(2.0 \%)$ & \\
\hline \multicolumn{2}{|l|}{ Postoperative LVEDD $(\mathrm{cm})$} & $5.67 \pm 0.49$ & $5.40 \pm 0.54$ & $0.007^{*}$ \\
\hline \multicolumn{2}{|l|}{ Postoperative LVESD $(\mathrm{cm})$} & $4.43 \pm 0.68$ & $3.44 \pm 0.57$ & $0.002^{*}$ \\
\hline \multicolumn{2}{|l|}{ Postoperative EF $(\mathrm{cm})$} & $38.98 \pm 8.50$ & $59.44 \pm 6.88$ & $<0.001^{*}$ \\
\hline \multicolumn{2}{|l|}{ 30-days mortality } & $10(8.3 \%)$ & $1(2.0 \%)$ & 0.126 \\
\hline
\end{tabular}

Table 3. Preoperative and postoperative outcomes comparison in low EF group. Values are presented as numbers (\%) or mean $+\mathrm{SD}$. ${ }^{*}$ indicate significant difference between the groups $(\mathrm{p}<0.05)$.

\begin{tabular}{cccc}
\hline & Preoperative & Postoperative & P value \\
\hline (n=120) & $(\mathrm{n}=110)$ & \\
\hline NYHA class & $3.31 \pm 0.56$ & $1.50 \pm 0.61$ & $<0.001^{\star}$ \\
CCS grade & $3.11 \pm 0.55$ & $1.38 \pm 0.52$ & $<0.001^{\star}$ \\
LVEDD $(\mathrm{cm})$ & $5.79 \pm 0.53$ & $5.63 \pm 0.51$ & $0.002^{\star}$ \\
LVESD $(\mathrm{cm})$ & $4.58 \pm 0.70$ & $4.35 \pm 0.64$ & $0.001^{\star}$ \\
EF $(\%)$ & $37.49 \pm 2.89$ & $40.30 \pm 8.19$ & $<0.001^{\star}$
\end{tabular}

NYHA $=$ New York Heart Association, CCS $=$ Canadian cardiovascular society, EF $=$ ejection fraction, LVEDD = left ventricular end diastolic diameter, LVESD = left ventricular end systolic 
The post operative cerebrovascular events occurred in 6 patients (5.0\%). The 30-days mortality occurred in ten cases; seven patients died due to myocardial infarction (one intraoperatively, four before discharge and two patients were readmitted to $\mathrm{CCU}$ ), two patients were due to failure of weaning from $\mathrm{CPB}$ and. The last patient died from a non-cardiac cause.

Table 4 shows factors significantly associated with 30-days mortality including older age, female gender, diabetes, longer cross-clamp time, longer cardiopulmonary bypass time, intra-aortic balloon pump (IABP) insertion, myocardial infarction and lower ejection fraction postoperatively, ventricular tachycardia, and ventricular fibrillation.

\section{Discussion}

The aim of this study was to evaluate the effect of low EF on the results after CABG and identify the predictors of mortality.

In our study, the major adverse cardiac events (MACE) were higher in the group $1(\mathrm{EF}<40 \%)$ than group $2(\mathrm{EF} \geq 40)$ and non-fatal cerebrovascular events, non-fatal myocardial infarction, heart failure, infectious and neurological complications occurred more significantly in $\mathrm{EF}<40 \%$ patients.

In addition, we found a significantly higher number of grafts, total operative time, adrenaline and IABP insertion in group 1, which were compatible with the literature [5].

The need for mechanical ventilation, ICU and hospital stay were significantly longer in low EF [8]. This occurred due to $\mathrm{EF}<40 \%$ is associated with hemodynamic instability and the increased use of IABP and inotropes and these factors affected the duration of mechanical, ICU and hospital stay directly [8] [9].

Preoperative EF of the targeted study group improved in the immediate postoperative period, and the improvement continued at the three months follow-up. Patients with CAD and advanced ventricular dysfunction have poor prognoses with medical treatment alone despite recent advances. The coronary artery surgery study (CASS) study demonstrated that only $38 \%$ of medically treated patients ( $\mathrm{EF} \leq 35 \%)$ were alive and free of moderate or severe limitations 5 years after the onset of treatment. Surgical approaches to CAD patients with low EF include CABG, ventricular remodelling, and cardiac transplantation [10].

The study of Alderman and associates showed that patients with an EF $<35 \%$ treated with surgical approach had a 63\% 5-year survival rate compared with a $43 \%$ in the medically treated patients [11] [12] [13].

The 30 -days mortality in the present work occurred in $8.3 \%$ of the patients which was slightly higher than the reported series which ranged from $3.4 \%$ to $4.4 \%$ [5] [9] [14], this may be due to lack of medical awareness, vigorously avoidance of surgery and more aggressive disease pattern which is reflected in younger age patient group and poor targets.

In our study, mortality was significantly associated with both preoperative; as 
Table 4. Factors affecting 30 days mortality. Values are presented as numbers (\%) or mean + SD. ${ }^{*}$ indicate significant difference between the groups $(\mathrm{p}<0.05)$.

\begin{tabular}{|c|c|c|c|c|}
\hline & & Survival $(\mathrm{N}=110)$ & Mortality $(\mathrm{N}=10)$ & $P$ value \\
\hline \multicolumn{2}{|l|}{ Female } & $19(17.3 \%)$ & $7(70.0 \%)$ & $<0.001^{\star}$ \\
\hline \multicolumn{2}{|l|}{ Age (Years) } & $55.32 \pm 7.97$ & $61.40 \pm 7.01$ & $0.025^{\star}$ \\
\hline \multicolumn{2}{|l|}{$\mathrm{BMI}\left(\mathrm{Kg} / \mathrm{m}^{2}\right)$} & $29.74 \pm 4.44$ & $32.47 \pm 5.01$ & 0.127 \\
\hline \multicolumn{2}{|l|}{ Smoking } & $54(49.1 \%)$ & $3(30.0 \%)$ & 0.247 \\
\hline \multicolumn{2}{|l|}{ Dyslipidemia } & $51(46.4 \%)$ & $7(70.0 \%)$ & 0.152 \\
\hline \multicolumn{2}{|l|}{ Hypertension } & $59(53.6 \%)$ & $6(60.0 \%)$ & 0.698 \\
\hline \multirow[t]{2}{*}{ Diabetes Mellitus } & & $57(51.8 \%)$ & $10(100.0 \%)$ & $0.003^{*}$ \\
\hline & II & $6(5.5 \%)$ & $0(0.0 \%)$ & \\
\hline \multirow{2}{*}{ Preoperative NYHA class } & III & $68(61.8 \%)$ & $2(20.0 \%)$ & 0.222 \\
\hline & IV & $36(32.7 \%)$ & $8(80.0 \%)$ & \\
\hline \multicolumn{2}{|l|}{ Preoperative LVEDD (cm) } & $5.76 \pm 0.53$ & $6.07 \pm 0.49$ & 0.077 \\
\hline \multicolumn{2}{|l|}{ Preoperative LVESD $(\mathrm{cm})$} & $4.55 \pm 0.69$ & $4.85 \pm 0.82$ & 0.197 \\
\hline \multicolumn{2}{|l|}{ Preoperative EF (\%) } & $37.60 \pm 2.95$ & $36.20 \pm 2.09$ & 0.145 \\
\hline \multicolumn{2}{|l|}{ Number of grafts } & $3.13 \pm 1.01$ & $3.00 \pm 0.67$ & 0.691 \\
\hline \multicolumn{2}{|l|}{ CBP time (min) } & $108.49 \pm 36.89$ & $148.70 \pm 40.12$ & $0.001^{*}$ \\
\hline \multicolumn{2}{|l|}{ ACC time (min) } & $64.77 \pm 22.67$ & $88.19 \pm 31.94$ & $0.003^{*}$ \\
\hline \multicolumn{2}{|l|}{ Total operative time (hour) } & $5.38 \pm 0.95$ & $6.82 \pm 1.03$ & $<0.001^{*}$ \\
\hline \multicolumn{2}{|c|}{ DC shock application (intra-operative) } & $44(40.0 \%)$ & $7(70.0 \%)$ & 0.066 \\
\hline \multicolumn{2}{|c|}{ Intra operative complications } & $2(1.8 \%)$ & $6(60.0 \%)$ & $<0.001^{\star}$ \\
\hline \multicolumn{2}{|l|}{ Re exploration for bleeding } & $7(6.3 \%)$ & $0(0.00 \%)$ & 0.410 \\
\hline \multicolumn{2}{|c|}{ Duration of mechanical ventilation (hour) } & $16.99 \pm 21.67$ & $28.75 \pm 19.42$ & 0.096 \\
\hline \multicolumn{2}{|l|}{ ICU stay (days) } & $3.84 \pm 1.93$ & $2.84 \pm 1.70$ & 0.116 \\
\hline \multicolumn{2}{|c|}{ Postoperative inotropic support } & $83(75.4 \%)$ & $10(100.0 \%)$ & 0.075 \\
\hline \multirow[t]{2}{*}{ IABP insertion } & & $12(10.9 \%)$ & $9(90.0 \%)$ & $<0.001^{\star}$ \\
\hline & $\mathrm{AF}$ & $51(46.3 \%)$ & $2(20.0 \%)$ & 0.107 \\
\hline \multirow{3}{*}{ Arrhythmia } & Nodal & $4(3.6 \%)$ & $0(0.00 \%)$ & 0.539 \\
\hline & V Tach & $4(4.5 \%)$ & $3(30.0 \%)$ & $0.002^{*}$ \\
\hline & VF & $6(5.5 \%)$ & $5(50.0 \%)$ & $0.002^{*}$ \\
\hline \multicolumn{2}{|l|}{ Cerebrovascular events } & $5(4.5 \%)$ & $1(10.0 \%)$ & 0.448 \\
\hline \multicolumn{2}{|l|}{ Myocardial infarction } & $13(11.8 \%)$ & $7(70.0 \%)$ & $<0.001^{\star}$ \\
\hline \multicolumn{2}{|l|}{ ICU readmission } & $14(12.7 \%)$ & $1(10.0 \%)$ & 0.803 \\
\hline \multicolumn{2}{|c|}{ Early postoperative LVEED $(\mathrm{cm})$} & $5.63 \pm 0.51$ & $5.99 \pm 0.44$ & $0.033^{*}$ \\
\hline \multicolumn{2}{|c|}{ Early postoperative LVESD (cm) } & $4.35 \pm 0.64$ & $5.31 \pm 0.37$ & $<0.001^{\star}$ \\
\hline Early postoperative EF (\%) & & $40.30 \pm 8.19$ & $21.46 \pm 1.93$ & $<0.001^{*}$ \\
\hline
\end{tabular}


well as intraoperative risk factors. These predictors included female gender, older age, diabetes mellitus, longer cardiopulmonary bypass, cross-clamp time and operative times, IABP insertion, ventricular tachycardia, and ventricular fibrillation, myocardial infarction and lower early ejection fraction postoperatively.

\section{Conclusion}

Our conclusion is that $\mathrm{CABG}$ in patients with $\mathrm{EF}<40 \%$ is frequently associated with more complications than others with mid-range or normal ejection fraction; however it improves the targeted clinical outcomes and the echocardiographic indicators of functional improvements.

\section{Conflicts of Interest}

The authors declare no conflicts of interest regarding the publication of this paper.

\section{References}

[1] Natarajan, A., Samadian, S. and Clark, S. (2007) Coronary Artery Bypass Surgery in Elderly People. Postgraduate Medical Journal, 83, 154-158. https://doi.org/10.1136/pgmj.2006.049742

[2] Philippe, K., William, W., Volkmar, F., et al. (2014) ESC/EACTS Guidelines on Myocardial Revascularization. European Heart Journal, 35, 2541-2619. https://doi.org/10.1093/eurheartj/ehu278

[3] Baig, K., Harling, L., Papanikitas, J., et al. (2013) Does Coronary Artery Bypass Grafting Improve Quality of Life in Elderly Patients? Interactive CardioVascular and Thoracic Surgery, 17, 542-553. https://doi.org/10.1093/icvts/ivt220

[4] Inamdar, A., Shende, S. and Inamdar, S. (2017) Outcome of Coronary Artery Bypass Graft Surgery in Patients with Low Ejection Fraction. Medical Journal of Dr. D. Y. Patil Vidyapeeth, 10, 162. https://doi.org/10.4103/0975-2870.202107

[5] Trachiotis, G.D., Weintraub, W.S., Johnston, T.S., Jones, E.L., Guyton, R.A. and Craver, J.M. (1998) Coronary Artery Bypass Grafting in Patients with Advanced Left Ventricular Dysfunction. The Annals of Thoracic Surgery, 66, 1632-1639. https://doi.org/10.1016/S0003-4975(98)00773-5

[6] Pieri, M., Belletti, A., Monaco, F., et al. (2016) Outcome of Cardiac Surgery in Patients with Low Preoperative Ejection Fraction. BMC Anesthesiology, 16, 97. https://doi.org/10.1186/s12871-016-0271-5

[7] Thygesen, K., Alpert, J.S. and White, H.D. (2007) Joint ESC/ACCF/AHA/WHF Task Force for the Redefinition of Myocardial Infarction. Universal Definition of Myocardial Infarction. European Heart Journal, 28, 2525-2538.

[8] Davoodi, S., Karimi, A., Ahmadi, S.H., et al. (2008) Coronary Artery Bypass Grafting in Patients with Low Ejection Fraction: The Effect of Intra-Aortic Balloon Pump Insertion on Early Outcome. Indian Journal of Medical Sciences, 62, 314-322. https://doi.org/10.4103/0019-5359.42482

[9] Veli, K., Faisal, H., Michelle, L., et al. (2005) Coronary Artery Bypass Grafting in Patients with Low Ejection Fraction, Surgery for Coronary Artery Disease. Circulation, 112, 344-350.

[10] Gupta, M., Mishra, P.K., Shoeb, M., Agarwal, A. and Prasad, J. (2017) A Compari- 
son of Clinical Outcomes of LVEF $\leq 35 \%$ versus LVEF > $35 \%$ in Off-Pump Coronary Artery Bypass Graft Surgery. International Surgery Journal, 4, 1908-1912. https://doi.org/10.18203/2349-2902.isj20172011

[11] Alderman, E.L., Fisher, L.D. and Litwin, P. (1983) Results of Coronary Artery Surgery in Patients with Poor Left Ventricular Function (CASS). Circulation, 68, 785-795. https://doi.org/10.1161/01.CIR.68.4.785

[12] Passamani, E., Davis, K.B., Gillespie, M.J. and Killip, T. (1985) A Randomized Trial of Coronary Artery Bypass Surgery: Survival of Patients with a Low Ejection Fraction. The New England Journal of Medicine, 312, 1665-1671. https://doi.org/10.1056/NEJM198506273122603

[13] Singh, P., Sethi, N., Kaur, N. and Kozman, H. (2015) Revascularization in Severe Left Ventricular Dysfunction: Does Myocardial Viability Even Matter? Clinical Medicine Insights. Cardiology, 9, 105-109. https://doi.org/10.4137/CMC.S18755

[14] Appoo, J., Norris, C., Merali, S., et al. (2004) Long-Term Outcome of Isolated Coronary Artery Bypass Surgery in Patients with Severe Left Ventricular Dysfunction. Circulation, 110, II-13-II-17. https://doi.org/10.1161/01.CIR.0000138345.69540.ed 